\title{
PROCESO DE EVALUACIÓN FORMATIVA EN LA REALIZACIÓN DE UN VIDEOJUEGO PARA TECNOLOGÍA
}

Formative assessment process in the elaboration of a videogame for Technology subject Processo de avaliação formativa em fazer um videogame para Tecnologia

\section{César Lozano Gallego}

IES Valles del Luna, Santa María del Páramo (León), España. Teléfono: +34 6992683

\section{Correo electrónico cesar.lozano.gallego@gmail.com}

\section{Resumen}

Se presenta un caso práctico y real del proceso de evaluación formativa aplicado en Tecnología ( $\left.4^{\circ} \mathrm{ESO}\right)$ en el IES Valles del Luna de Santa María del Páramo (León). Tomando como referencia el tema de "Programación informática” del curso, los alumnos diseñaron y elaboraron un videojuego de coches utilizando el lenguaje de programación de MSWLogo. Previamente se les presentó la escala descriptiva ('rúbrica') con los diferentes aspectos a valorar, así como sus distintos niveles de logro y valor asignado.

Palabras clave: Evaluación formativa; Rúbrica; Tecnología, programación

\section{Abstract}

A practical and real case of the process of formative assessment applied in Technology ( $\left.4^{\circ} \mathrm{ESO}\right)$ in the IES Valles del Luna (Santa María del Páramo, León) is presented. Based on the "Computer Programming" theme of the course, students designed and developed a car videogame using the MSWLogo programming language. Previously the descriptive scale ('rubric') was presented with the different aspects to be evaluated, as well as their different levels of achievement and assigned value.

Keywords: Formative assessment; rubric; Technology, computer programming

\section{Resumo}

Um processo de avaliação formativa prático e real aplicado Tecnologia ( $4^{\circ}$ ESO) na IES Valles del Luna (Santa María del Páramo ,León) é apresentado. Tomando o tema "Programação", os alunos projetado e desenvolvido um carro videogame usando a 
linguagem de programação MSWLogo. Anteriormente, eles apresentados com a escala descritiva ('rubrica') com os diferentes aspectos a serem avaliados, bem como diferentes níveis de realização e valor atribuído.

Palavras-chave: avaliação formativa; rubrica; Tecnologia, programação

\section{Introducción}

La elaboración de un videojuego de coches puede resultar una actividad entretenida para el alumno y a la vez útil de cara al aprendizaje de los principales métodos de programación informática que existen. Así, se ha llevado a cabo una Unidad Didáctica utilizando como método la evaluación formativa, cuya finalidad principal no es calificar al alumno, sino disponer de información que permita saber cómo ayudar al alumnado a mejorar y aprender más,... y que sirva a su vez para que los profesores aprendamos a hacer nuestro trabajo cada vez mejor (López-Pastor et al., 2006). Para ello se ha elaborado una rúbrica, de modo que el alumno y el profesor pueden en todo momento constatar, valorar y tomar decisiones para optimizar el proceso de enseñanzaaprendizaje que tiene lugar, desde un perspectiva humanizadora y no como mero fin calificador (López Pastor et al, 2009).

\section{Contextualización}

La experiencia se desarrolló en el Instituto de Educación Secundaria "Valles del Luna" de Santa María del Páramo (León), centro que oferta Enseñanza Secundaria Obligatoria y Bachillerato. El centro dispone de línea bilingüe (inglés), si bien esta experiencia tuvo lugar en la materia de Tecnología durante el segundo trimestre, con el grupo no bilingüe de $4^{\circ} \mathrm{ESO}$, compuesto por 6 alumnos. Se llevó a cabo la Unidad Didáctica (UD) "Páramo Kart”, con el objetivo de programar un videojuego de coches utilizando el lenguaje de programación MSWLogo.

Los objetivos específicos se centraron en que el alumno fuera capaz de:

- Conocer la técnica de programación desde sus inicios.

- Elaborar un videojuego real y motivador con un lenguaje de programación sencillo.

- Utilizar instrucciones básicas de programación. 
- Utilizar procedimientos recursivos para la programación.

- Utilizar la escala de valoración como instrumento asociado a una evaluación formativa

\section{Diseño y desarrollo}

La UD duró 24 h (6 semanas x 4 h semanales) y se desarrolló en cinco fases:

1. Conocimiento de los diferentes lenguajes de programación: al inicio de la unidad se repasaron los principales lenguajes de programación, así como las diferentes técnicas mediante la elaboración de mapas conceptuales y diagramas de procesos.

2. Conocimiento de las instrucciones y procedimientos necesarios para programar en MSWLogo: se explicaron las diferentes instrucciones que forman parte del lenguaje de programación de MSWLogo, y se elaboraron diferentes pruebas con instrucciones y procedimientos para poner en uso lo aprendido en clase.

3. Explicación de los requisitos necesarios en el videojuego: este trabajo se llevó a cabo de forma individual. Cada alumno tuvo que programar su videojuego de coches. Desde el inicio se hizo entrega de la escala de valoración (“rúbrica”) donde aparecen los criterios con los que van a ser evaluados y calificados (Tabla 1).

4. Elaboración del videojuego: la UD se desarrolló completamente durante las clases de Tecnología. Los alumnos comenzaron elaborando pequeños programas de prueba, donde irían poniendo en práctica las diferentes instrucciones y procedimientos explicados en clase.

5. Prueba de los videojuegos de los alumnos: tras la entrega final, cada alumno comprobó el funcionamiento de los videojuegos diseñados por sus compañeros. Se realizó un pequeño debate sobre los puntos fuertes y aspectos a mejorar de cada videojuego.

\section{Evaluación}

La evaluación formativa utilizada en esta UD seconvirtió en un elemento clave durante el proceso de adquisición de habilidades en la programación informática, pues cada alumno realizó su videojuego buscando e investigando para alcanzar los mayores niveles de logro descritos en la escala de valoración (Tabla 1). Esta escala (rúbrica) marcó la actividad de los alumnos, siendo consultada durante todas las sesiones de 
elaboración del videojuego: cada alumno fue capaz de identificar sus propios errores y de buscar las alternativas para solucionarlos posteriormente.

Así mismo, la escala sirvió como instrumento de evaluacióndurante la fase final de la unidad, ya que, tras la puesta en marcha de los videojuegos, cada alumno procedió a la autoevaluación y coevaluación através de la cumplimentación de dicha escala. En este enlace https://www.youtube.com/watch?v=IUc_SL3b0jw puede verse un ejemplo de videojuego realizado por uno de los alumnos.

Del total de 6 alumnos, los resultados obtenidos fueron los siguientes:

- Sobresaliente: 5 alumnos

- Notable: 1 alumno.

Como puede verse, la calificación obtenida por el alumnado fue muy positiva, así como sus sensaciones tras haber llevado a cabo la UD mediante evaluación formativa. Los alumnos señalaron que el establecimiento previo de una escala de valoración les resultó muy útil, por lo que tanto su proceso de aprendizaje como el resultado final fueron excelentes.

\section{Conclusiones}

Por un lado, mediante esta experiencia se comprueba que los alumnos han sido responsables con la metodología propuesta, pues han seguido cada uno de los criterios a valorar establecidos en la rúbrica entregada inicialmente. De esta manera, identificaron los aspectos positivos y reconocieron los puntos negativos de su propio trabajo y el de los compañeros.

Por otro lado, es evidente que tanto el nivel de autonomía del alumnado como su competencia de aprender a aprender se han visto incrementados, lo que puede ser debido a los procesos de autoevaluación y coevaluación llevados a cabo por ellos mismos.

\section{Referencias}

López-Pastor, V. M. (coord.) (2009). Evaluación formativa y compartida en educación superior. Propuestas, técnicas, instrumentos y experiencias. Madrid: Narcea. 